\title{
Imaging technologies from bench to bedside
}

Ravinder Reddy ${ }^{1 *}$ and Mohammad Haris ${ }^{2}$

The last few decades have seen tremendous advances in medicine that have enhanced understanding of pathophysiological processes at the cellular and molecular level, and led to the development of increasingly sophisticated diagnostic imaging technologies. Early detection of disease induced molecular and functional changes before induction of irreversible structural changes is key for optimal treatment efficacy. Non-invasive imaging modalities, such as positron emission tomography (PET) [1], single photon emission computed tomography (SPECT) [2], computed tomography (CT) [3], optical tomographic technologies [4], magnetic resonance imaging (MRI) [5], ultrasound (US) [6], and X-rays play a vital role in both the diagnosis and monitoring of disease in response to therapy. These techniques cover a broad range of spatio-temporal resolution and varying degrees of sensitivity and specificity to different molecular changes, and in many cases provide complementary information $[7,8]$. Recently discovered molecular targets of various disease states, including oncology, neurodegenerative and neuropsychiatric, cardiovascular, and musculoskeletal pathologies, drive further developments in the imaging field to detect these new molecular markers. Ultimately, these technologies contribute to improved disease management and personalized patient care.

Standard-of-care medical imaging techniques such as $\mathrm{X}$-rays, US, CT and MRI provide exquisite structural details of human anatomy. These methods are the first-line techniques in clinic for diagnosis and characterization of disease, based primarily on structure/morphology such as size, texture and tissue attenuation [8]. In addition to providing diagnostic information, the US modality has the additional benefit of use as a therapeutic tool $[6,7,9]$.

Functional nuclear medicine techniques (PET and SPECT) provide a unique, non-invasive assessment of intracellular processes and enzyme trafficking, receptors and gene expression, and serve as the underpinnings of molecular medicine. These techniques provide

\footnotetext{
* Correspondence: krr@mail.med.upenn.edu

${ }^{1}$ Center for Magnetic Resonance and Optical Imaging, Perelman School of Medicine, Department of Radiology, University of Pennsylvania, 422 Curie Boulevard, Philadelphia, PA 19104-6100, USA

Full list of author information is available at the end of the article
}

non-invasive diagnostic information about biochemical and physiological process ranging from glucose metabolism to gene expression by evaluating the kinetics of shortlived radioisotope tracers. While many promising tracers have been synthesized that target a variety of metabolic pathways or specific markers ${ }^{18} \mathrm{~F}$-fluorodeoxyglucose (FDG), a glucose analogue is the main radiotracer in clinical practice today. In addition, these functional nuclear medicine techniques are also being used in research and clinical settings to detect and evaluate Alzheimer's disease, metabolic viability of cardiac tissues, in vivo gene expression, and in tracking of cancer metastasis to different organs [7,8,10-12].

MRI is one of the most powerful and versatile noninvasive techniques. The major advantage of MRI is that it provides high-resolution, three-dimensional images of tissue structure, as well as functional and metabolic information. Furthermore, MRI is performed in vivo without the use of any ionizing radiation, allowing for repeated study. Several advanced MRI methods have been introduced to monitor the structural [13], functional [14,15] as well as biochemical changes in various diseases. Magnetic resonance spectroscopy (MRS), which provides the information about the biochemical signatures, is an additional important clinical research tool to assess and characterize disease pathophysiology $[16,17]$.

Using MRS, enriched metabolites (e.g. ${ }^{13} \mathrm{C}$ enriched) can be used to probe endogenous reaction kinetics. Latest advances in chemical exchange saturation transfer (CEST) MRI show promise in detecting several endogenous metabolites and proteins with substantially enhanced sensitivity (at least an order of magnitude) compared to conventional MRS [18-25]. Recent developments in hyperpolarized imaging based on dynamic nuclear polarization (DNP) of ${ }^{13} \mathrm{C}$ enriched pyruvate are yielding highly promising preclinical results $[26,27]$ exploring in vivo reactions in oncology and other disease conditions. Some very preliminary results showing the promise of these methods in addressing clinical problems in patients have been demonstrated [28].

Optical imaging is another emerging imaging modality with high potential for improving diseases diagnosis and 
treatment, which can be readily set up at the patient's bedside or in the operating room [4,29-31]. Optical imaging uses non-ionizing radiation and offers potentially to image organs, tissues as well as smaller structures including cells and molecules using their unique photon absorption or scattering profiles. It also differentiates between native soft tissue and tissue labeled with endogenous or exogenous probes based on their wavelength dependent photon absorption or scattering pattern [32-35]. Despite limitations in their spatial resolution, optical imaging methods offer capabilities for studying functional and molecular events in different pathophysiological conditions. There are several techniques in optical imaging that are currently being used both in research and clinical setting for evaluating various diseases and therapeutic responses [30,36-38]. Potentially, optical imaging can also be combined with other imaging modalities to improve the patient's clinical management.

PET, SPECT and near-infrared reflectance fluorescence optical imaging techniques have relatively high sensitivity and can detect compounds with concentrations in micro- to pico-molar range [7]. Despite the high sensitivity these methods are beset by a relatively low spatial resolution (5 to $10 \mathrm{~mm}$ in clinical setting). Also, in many cases the emitting ligands may lose the specificity. One issue with nuclear medicine techniques is the use of nuclear radiation, which precludes their repeat use in short time spans. On the other hand, MRI provides high spatial resolution (in hundreds of micrometers range), but is relatively insensitive, in comparison to nuclear medicine techniques mentioned above; it requires concentrations of metabolites to be detected to be in the millimolar range and few endogenous molecules or metabolites can be imaged [39].

A milestone in the field of diagnostic imaging is the emergence of integrated structural and functional modalities such as combined PET-CT and PET-MRI $[40,41]$. These integrated modalities provide concurrent structural, molecular and functional information, improve the multimodal imaging correlations and ease the patient burden for multiple imaging sessions.

Combining these advanced imaging techniques will result in improved precision of the data that are intrinsically more sensitive to the underlying pathophysiology than the morphological features available in routine structural imaging. Over the years, all these powerful imaging techniques have been improving the way the diseases are diagnosed, therapeutic responses are monitored and dramatically enhancing the practice of medicine making it more prognostic, preventative and personalized. Despite these advances, many technological innovations in these imaging modalities are still in research setting. Transferring these technologies into clinical setting requires an intense collaborative effort between researchers in imaging physics, instrumentation, image processing, biologists, chemists, and regulatory bodies as well as clinicians from all branches of medicine. This journal section facilitates communication of advances in translating the imaging modalities from mere research tools to clinical setting. We welcome research articles from all the stakeholders in this field.

\section{Author details}

${ }^{1}$ Center for Magnetic Resonance and Optical Imaging, Perelman School of Medicine, Department of Radiology, University of Pennsylvania, 422 Curie Boulevard, Philadelphia, PA 19104-6100, USA. ${ }^{2}$ Research Branch, Sidra Medical and Research Center, Doha, Qatar.

Received: 24 February 2015 Accepted: 3 March 2015

Published online: 21 March 2015

\section{References}

1. Reivich M, Kuhl D, Wolf A, Greenberg J, Phelps M, Ido T, et al. The [18 F] fluorodeoxyglucose method for the measurement of local cerebral glucose utilization in man. Circ Res. 1979;44:127-37.

2. Keyes Jr JW, Orlandea N, Heetderks WJ, Leonard PF, Rogers WL. The Humongotron-a scintillation-camera transaxial tomograph. J Nucl Med. 1977;18:381-7.

3. Hounsfield GN. Computerized transverse axial scanning (tomography). 1. Description of system. Br J Radiol. 1973;46:1016-22.

4. Hillman EM, Amoozegar CB, Wang T, McCaslin AF, Bouchard MB, Mansfield J, et al. In vivo optical imaging and dynamic contrast methods for biomedical research. Philos Transact A Math Phys Eng Sci. 2011;369:4620-43.

5. Lauterbur PC. Image Formation by Induced Local Interactions: Examples Employing Nuclear Magnetic Resonance. Nature. 1973;242:190.

6. Liang HD, Blomley MJ. The role of ultrasound in molecular imaging. Br J Radio. 2003;76 Spec(No 2):S140-150.

7. James ML, Gambhir SS. A molecular imaging primer: modalities, imaging agents, and applications. Physiol Rev. 2012;92:897-965.

8. Yankeelov TE, Abramson RG, Quarles CC. Quantitative multimodality imaging in cancer research and therapy. Nat Rev Clin Oncol. 2014;11:670-80.

9. Wood AK, Schultz SM, Lee WM, Bunte RM, Sehgal CM. Antivascular ultrasound therapy extends survival of mice with implanted melanomas. Ultrasound Med Biol. 2010;36:853-7.

10. Johnson KA, Minoshima S, Bohnen NI, Donohoe KJ, Foster NL, Herscovitch P, et al. Appropriate use criteria for amyloid PET: a report of the Amyloid Imaging Task Force, the Society of Nuclear Medicine and Molecular Imaging, and the Alzheimer's Association. Alzheimers Dement. 2013;9:e-1-16.

11. Johnson KA, Sperling RA, Gidicsin CM, Carmasin JS, Maye JE, Coleman RE, et al. Florbetapir (F18-AV-45) PET to assess amyloid burden in Alzheimer's disease dementia, mild cognitive impairment, and normal aging. Alzheimers Dement. 2013;9:S72-83.

12. Mankoff DA, Pryma DA, Clark AS. Molecular imaging biomarkers for oncology clinical trials. J Nucl Med. 2014;55:525-8.

13. Le Bihan D. Diffusion MRI: what water tells us about the brain. EMBO Mol Med. 2014;6:569-73.

14. Biswal B, Yetkin FZ, Haughton VM, Hyde JS. Functional connectivity in the motor cortex of resting human brain using echo-planar MRI. Magn Reson Med. 1995;34:537-41.

15. Ogawa S, Tank DW, Menon R, Ellermann JM, Kim SG, Merkle H, et al. Intrinsic signal changes accompanying sensory stimulation: functional brain mapping with magnetic resonance imaging. Proc Natl Acad Sci U S A. 1992;89:5951-5.

16. Senft C, Hattingen E, Pilatus U, Franz K, Schanzer A, Lanfermann $H$, et al. Diagnostic value of proton magnetic resonance spectroscopy in the noninvasive grading of solid gliomas: comparison of maximum and mean choline values. Neurosurgery. 2009;65:908-13. discussion 913.

17. Jansen JF, Schoder H, Lee NY, Stambuk HE, Wang Y, Fury MG, et al. Tumor metabolism and perfusion in head and neck squamous cell carcinoma: pretreatment multimodality imaging with $1 \mathrm{H}$ magnetic resonance spectroscopy, dynamic contrast-enhanced MRI, and [18F]FDG-PET. Int J Radiat Oncol, Biol, Phys. 2012;82:299-307. 
18. Kogan F, Hariharan H, Reddy R. Chemical Exchange Saturation Transfer (CEST) Imaging: Description of Technique and Potential Clinical Applications. Curr Radiol Rep. 2013;1:102-14.

19. Zhou J, Tryggestad E, Wen Z, Lal B, Zhou T, Grossman R, et al. Differentiation between glioma and radiation necrosis using molecular magnetic resonance imaging of endogenous proteins and peptides. Nat Med. 2011;17:130-4.

20. Cai $K$, Haris M, Singh A, Kogan F, Greenberg JH, Hariharan $H$, et al. Magnetic resonance imaging of glutamate. Nat Med. 2012;18:302-6.

21. Haris M, Singh A, Cai K, Kogan F, McGarvey J, Debrosse C, et al. A technique for in vivo mapping of myocardial creatine kinase metabolism. Nat Med. 2014;20:209-14.

22. Walker-Samuel S, Ramasawmy R, Torrealdea F, Rega M, Rajkumar V, Johnson SP, et al. In vivo imaging of glucose uptake and metabolism in tumors. Nat Med. 2013;19:1067-72

23. van Zijl PC, Jones CK, Ren J, Malloy CR, Sherry AD. MRI detection of glycogen in vivo by using chemical exchange saturation transfer imaging (glycoCEST). Proc Natl Acad Sci U S A. 2007;104:4359-64.

24. Chan KW, Liu G, Song X, Kim H, Yu T, Arifin DR, et al. MRI-detectable pH nanosensors incorporated into hydrogels for in vivo sensing of transplanted-cell viability. Nat Mater. 2013;12:268-75.

25. Ling W, Regatte RR, Navon G, Jerschow A. Assessment of glycosaminoglycan concentration in vivo by chemical exchange-dependent saturation transfer (gagCEST). Proc Natl Acad Sci U S A. 2008;105:2266-70.

26. Golman K, In 't Zandt R, Thaning M. Real-time metabolic imaging. Proc Natl Acad Sci U S A. 2006:103:11270-5.

27. Golman K, Zandt RI, Lerche M, Pehrson R, Ardenkjaer-Larsen JH. Metabolic imaging by hyperpolarized $13 \mathrm{C}$ magnetic resonance imaging for in vivo tumor diagnosis. Cancer Res. 2006;66:10855-60.

28. Nelson SJ, Kurhanewicz J, Vigneron DB, Larson PE, Harzstark AL, Ferrone M, et al. Metabolic imaging of patients with prostate cancer using hyperpolarized [1-(1)(3)C]pyruvate. Sci Transl Med. 2013;5:198ra108.

29. Taruttis A, Ntziachristos $V$. Translational optical imaging. AJR Am J Roentgenol. 2012;199:263-71

30. Dhawan AP, D'Alessandro B, Fu X. Optical imaging modalities for biomedical applications. IEEE Rev Biomed Eng. 2010;3:69-92.

31. Chance B. Near-infrared images using continuous, phase-modulated, and pulsed light with quantitation of blood and blood oxygenation. Ann N Y Acad Sci. 1998:838:29-45

32. Michalet X, Pinaud FF, Bentolila LA, Tsay JM, Doose S, Li JJ, et al. Quantum dots for live cells, in vivo imaging, and diagnostics. Science. 2005;307:538-44.

33. Chalfie M, Tu Y, Euskirchen G, Ward WW, Prasher DC. Green fluorescent protein as a marker for gene expression. Science. 1994;263:802-5.

34. Ntziachristos $\mathrm{V}$, Tung $\mathrm{CH}$, Bremer $\mathrm{C}$, Weissleder R. Fluorescence molecular tomography resolves protease activity in vivo. Nat Med. 2002;8:757-60.

35. Heim N, Garaschuk O, Friedrich MW, Mank M, Milos Rl, Kovalchuk Y, et al. Improved calcium imaging in transgenic mice expressing a troponin C-based biosensor. Nat Methods. 2007:4:127-9.

36. Culver JP, Choe R, Holboke MJ, Zubkov L, Durduran T, Slemp A, et al. Three-dimensional diffuse optical tomography in the parallel plane transmission geometry: evaluation of a hybrid frequency domain/continuous wave clinical system for breast imaging. Med Phys. 2003;30:235-47.

37. Durduran T, Yodh AG. Diffuse correlation spectroscopy for non-invasive, micro-vascular cerebral blood flow measurement. Neuroimage. 2014:85(Pt 1):51-63.

38. Zeff BW, White BR, Dehghani H, Schlaggar BL, Culver JP. Retinotopic mapping of adult human visual cortex with high-density diffuse optical tomography. Proc Natl Acad Sci U S A. 2007;104:12169-74.

39. Beckmann N. In Vivo Magnetic Resonance Techniques and Drug Discovery. Braz J Phys. 2006;36:16

40. Judenhofer MS, Wehrl HF, Newport DF, Catana C, Siegel SB, Becker M, et al. Simultaneous PET-MRI: a new approach for functional and morphological imaging. Nat Med. 2008;14:459-65.

41. Even-Sapir E, Keidar Z, Bar-Shalom R. Hybrid imaging (SPECT/CT and PET/CT)improving the diagnostic accuracy of functional/metabolic and anatomic imaging. Semin Nucl Med. 2009:39:264-75.

\section{Submit your next manuscript to BioMed Central and take full advantage of:}

- Convenient online submission

- Thorough peer review

- No space constraints or color figure charges

- Immediate publication on acceptance

- Inclusion in PubMed, CAS, Scopus and Google Scholar

- Research which is freely available for redistribution 